\title{
Antitumor activity of the ERK inhibitor SCH722984 against BRAF mutant, NRAS mutant and wild-type melanoma
}

\author{
Deborah JL Wong ${ }^{1 \dagger}$, Lidia Robert ${ }^{1 \dagger}$, Mohammad S Atefi ${ }^{1}$, Amanda Lassen ${ }^{1}$, Geetha Avarappatt ${ }^{1,7}$, \\ Michael Cerniglia', Earl Avramis', Jennifer Tsoi ${ }^{2}$, David Foulad ${ }^{1}$, Thomas G Graeber ${ }^{2}$, Begonya Comin-Anduix ${ }^{3,4}$, \\ Ahmed Samatar ${ }^{5}$, Roger S Lo ${ }^{2,4,6}$ and Antoni Ribas ${ }^{1,2,3,4^{*}}$
}

\begin{abstract}
Background: In melanoma, dysregulation of the MAPK pathway, usually via BRAF ${ }^{V 600}$ or NRAS ${ }^{\mathrm{Q} 61}$ somatic mutations, leads to constitutive ERK signaling. While BRAF inhibitors are initially effective for BRAF-mutant melanoma, no FDA-approved targeted therapies exist for BRAF-inhibitor-resistant $B R A F^{V 600}$, NRAS mutant, or wild-type melanoma.

Methods: The 50\% inhibitory concentration (IC50) of SCH772984, a novel inhibitor of ERK1/2, was determined in a panel of 50 melanoma cell lines. Effects on MAPK and AKT signaling by western blotting and cell cycle by flow cytometry were determined.

Results: Sensitivity fell into three groups: sensitive, 50\% inhibitory concentration $\left(I C_{50}\right)<1 \mu \mathrm{M}$; intermediately sensitive, $\mathrm{I}_{50}$ 1-2 $\mu \mathrm{M}$; and resistant, $>2 \mu \mathrm{M}$. Fifteen of 21 (71\%) BRAF mutants, including 4 with innate vemurafenib resistance, were sensitive to SCH772984. All three (100\%) BRAF/NRAS double mutants, 11 of 14 (78\%) NRAS mutants and 5 of 7 (71\%) wild-type melanomas were sensitive. Among BRAF ${ }^{V 600}$ mutants with in vitro acquired resistance to vemurafenib, those with MAPK pathway reactivation as the mechanism of resistance were sensitive to SCH772984. SCH772984 caused G1 arrest and induced apoptosis.
\end{abstract}

Conclusions: Combining vemurafenib and SCH722984 in BRAF mutant melanoma was synergistic in a majority of cell lines and significantly delayed the onset of acquired resistance in long term in vitro assays. Therefore, SCH772984 may be clinically applicable as a treatment for non-BRAF mutant melanoma or in BRAF-mutant melanoma with innate or acquired resistance, alone or in combination with BRAF inhibitors.

Keywords: ERK inhibitor, BRAF inhibitor, Melanoma, Targeted therapy, Acquired resistance

\section{Background}

Currently, targeted therapy for metastatic melanoma hinges on determining BRAF mutational status. Approximately $50 \%$ of all melanomas contain an activating $B R A F^{V 600}$, a serine-threonine kinase which functions as an oncogenic driver. This constitutively activates the MAPK pathway via sequential phosphorylation of MEK and then ERK. Vemurafenib and dabrafenib, two type I RAF inhibitors,

\footnotetext{
* Correspondence: aribas@mednet.ucla.edu

${ }^{\dagger}$ Equal contributors

'Department of Medicine, Division of Hematology-Oncology, University of California Los Angeles (UCLA), 11-934 Factor Building, Los Angeles, CA, USA 2Department of Molecular and Medical Pharmacology, UCLA, Los Angeles, CA, USA

Full list of author information is available at the end of the article
}

selectively inhibit $B R A F^{V 600}$, leading to improvements in both progression free survival and overall survival for patients with this disease [1-3]. However, BRAF inhibition is not effective in the remaining $50 \%$ of $B R A F$ wild-type melanoma, including $N R A S^{\mathrm{Q} 61}$ melanoma. Indeed, treatment of non-BRAF mutant cells with dabrafenib or vemurafenib would result in paradoxical activation of the MAPK pathway, mediated by CRAF $[4,5]$.

For $B R A F^{V 600}$ mutant melanoma, initial response rate to $\mathrm{BRAF}$ inhibitors (BRAFi) is beyond $50 \%$, though median duration of response is only 6-7 months. Resistance to BRAFi has been reported to occur via MAPK-dependent and -independent mechanisms. Reported MAPK-dependent mechanisms include secondary mutations in NRAS [6] or

\section{() Biomed Central}

(c) 2014 Wong et al.; licensee BioMed Central Ltd. This is an Open Access article distributed under the terms of the Creative Commons Attribution License (http://creativecommons.org/licenses/by/4.0), which permits unrestricted use, distribution, and reproduction in any medium, provided the original work is properly credited. The Creative Commons Public Domain Dedication waiver (http://creativecommons.org/publicdomain/zero/1.0/) applies to the data made available in this article, unless otherwise stated. 
$M E K$ [7,8], upregulation of the COT pathway [9], mutant $B R A F$ gene amplification [10] or development of $\mathrm{BRAF}^{\mathrm{V} 600 \mathrm{E}}$ splice variants [11]. MAPK-independent mechanisms of acquired resistance also occur, through the upregulation of receptor tyrosine kinases (RTKs), such as the plateletderived growth factor beta (PDGFR $\beta$ ) [6], or the insulin growth factor receptor 1 (IGF1R), or deletions of PTEN [12]. These all lead primarily to enhanced PI3K/AKT/ mTOR signaling rather than reactivation of the MAPK pathway. These mechanisms of acquired resistance are generally mutually exclusive and predict for susceptibility to inhibition with other targeted therapies in vitro; cell lines with secondary $N R A S^{\mathrm{Q} 61}$ mutations remain sensitive to a MEK inhibitor [13] (MEKi), while cell lines displaying RTK upregulation are cross-resistant to a MEKi but sensitive to a PI3K, AKT or mTOR inhibitor in combination with vemurafenib $[14,15]$.

Combining BRAFi and MEKi delays the development of resistance in vitro compared to treatment with BRAFi or MEKi alone [16,17]. Likewise, a phase I/II clinical trial of dabrafenib and trametinib in $B R A F^{V 600}$ mutant metastatic melanoma resulted in progression-free survival of 9.4 months compared to 5.8 months in patients treated with dabrafenib alone. Response rates for the combination and dabrafenib alone treatments were $76 \%$ and $54 \%$, respectively [2]. However, resistance develops both in vitro and in vivo to this combination, thus additional treatments for melanoma are needed.

MEKi may have clinical activity in NRAS mutant melanoma. In vitro, inhibition occurs at nanomolar concentrations [13]. Resistance to MEKi is MAPK dependent [18-20]. In vivo, MEK inhibitors are effective in NRAS-mutated melanoma, though therapeutic activity is modest compared to BRAFi in BRAF mutant melanoma $[21,22]$.

Inhibition of ERK1 and ERK2 (ERK1/2) is a promising strategy to address both innate and acquired resistance to BRAFi and MEKi, regardless of the upstream mechanism(s) of MAPK reactivation. ERK1/2, the main downstream effectors of the MAPK pathway, activate proteins such as RSK and transcription factors needed to regulate cellular growth and survival [23,24] such as cyclin D1, which promotes progression through the $\mathrm{G} 1$ phase of the cell cycle [25]. There is extensive crosstalk between MAPK and PI3K/AKT pathways [26]. While some data indicate that activation of the MAPK pathway may decrease AKT signaling [27], cross-activation of the PI3K/AKT/mTOR pathway has been shown to be mediated directly by activation of ERK or via activation of RSK, leading to activation of mTORC1 $[28,29]$. Cross-inhibition versus cross-activation may vary based on cellular context or be timing dependent. Therefore, inhibiting ERK may result in inhibition of the oncogenic MAPK signaling in most melanomas, with added effects of partially inhibiting proliferative signals through the PI3K/AKT/ mTOR pathway.

SCH772984 is a potent, ATP competitive and noncompetitive inhibitor of ERK 1/2, with additional allosteric properties that inhibit ERK activation/phosphorylation by MEK [30]. It has been shown to be effective at nanomolar concentrations in multiple tumor cell lines including breast, colon, and melanoma [30]. SCH772984 specificity for ERK1/2 kinases occurs at concentrations up to $1 \mu \mathrm{M}$ and it inhibits phosphorylation of downstream ERK targets such as RSK. Given its specificity for ERK and the potential for ERK inhibition to inhibit both MAPK and PI3K/AKT pathways, we evaluated the susceptibility of wild-type, mutant BRAF- or NRAS-melanoma, and BRAF-mutant melanoma with acquired BRAFi resistance. We also tested the effect of combined BRAF and ERK inhibition on BRAF-mutant melanoma in short-term and long-term cultures to determine if combination therapy would result in improved inhibition or delay the development of resistance in vitro.

\section{Results \\ BRAF-mutant melanoma cell lines are sensitive to ERK inhibition}

Twenty-one melanoma cell lines containing mutations in the $B R A F$ gene were evaluated to determine sensitivity to SCH772984 (ERKi). As a comparison, sensitivity to vemurafenib was also determined. $B R A F^{V 600 E}$ was the most frequently observed BRAF mutation, present in 17 of 21 cell lines. M381 contains $B R A F^{V 600 R}$ substitution, M414 contains $B R A F^{V 600 K}$, M417 contains $B R A F^{G 466 E}$ and M420 contains BRAF $F^{L 597 S}$ mutation. Among the 21 cell lines, sensitivity to vemurafenib or $\mathrm{SCH}-772984$ fell into 3 groups: highly sensitive (50\% inhibitory concentration, $\left.\mathrm{IC}_{50}<1 \mu \mathrm{M}\right)$, intermediate sensitivity $\left(\mathrm{IC}_{50} 1-2 \mu \mathrm{M}\right)$ and resistant $\left(\mathrm{IC}_{50}>2 \mu \mathrm{M}\right)$. 15 cell lines were highly sensitive to $\mathrm{SCH}-772984$ with $\mathrm{IC}_{50}$ less than or equal to $1 \mu \mathrm{M}$. Of the 12 cell lines highly sensitive to vemurafenib, all contain $B R A F^{V 600 E}$ and were also sensitive to $\mathrm{SCH}$ 772984. Interestingly, M399, M414, M308, and M409 were sensitive to SCH-772984 but only intermediately sensitive (M399, M409 and M414) or resistant (M308) to vemurafenib. With the exception of M414, all non-V600E mutants were resistant to both vemurafenib and SCH772984. (Figure 1A). As a comparison, sensitivity to the MEKi trametinib segregated all cell lines into three different groups: highly sensitive $\left(\mathrm{IC}_{50}<2 \mathrm{nM}\right)$, intermediately sensitive $\left(\mathrm{IC}_{50} 2-30 \mathrm{nM}\right)$ and resistant $\left(\mathrm{IC}_{50}>30 \mathrm{nM}\right)$ (Additional file 1: Figure S1). In general, cell lines sensitive to SCH772984 were also sensitive to trametinib.

We next determined a time-course of SCH772984 on MAPK and PI3K/AKT pathway signaling for M238, a SCH772984-sensitive $B R A F^{V 600 E}$-mutant melanoma cell line and M233, a SCH772984-resistant $B R A F^{V 600 E}$-mutant 


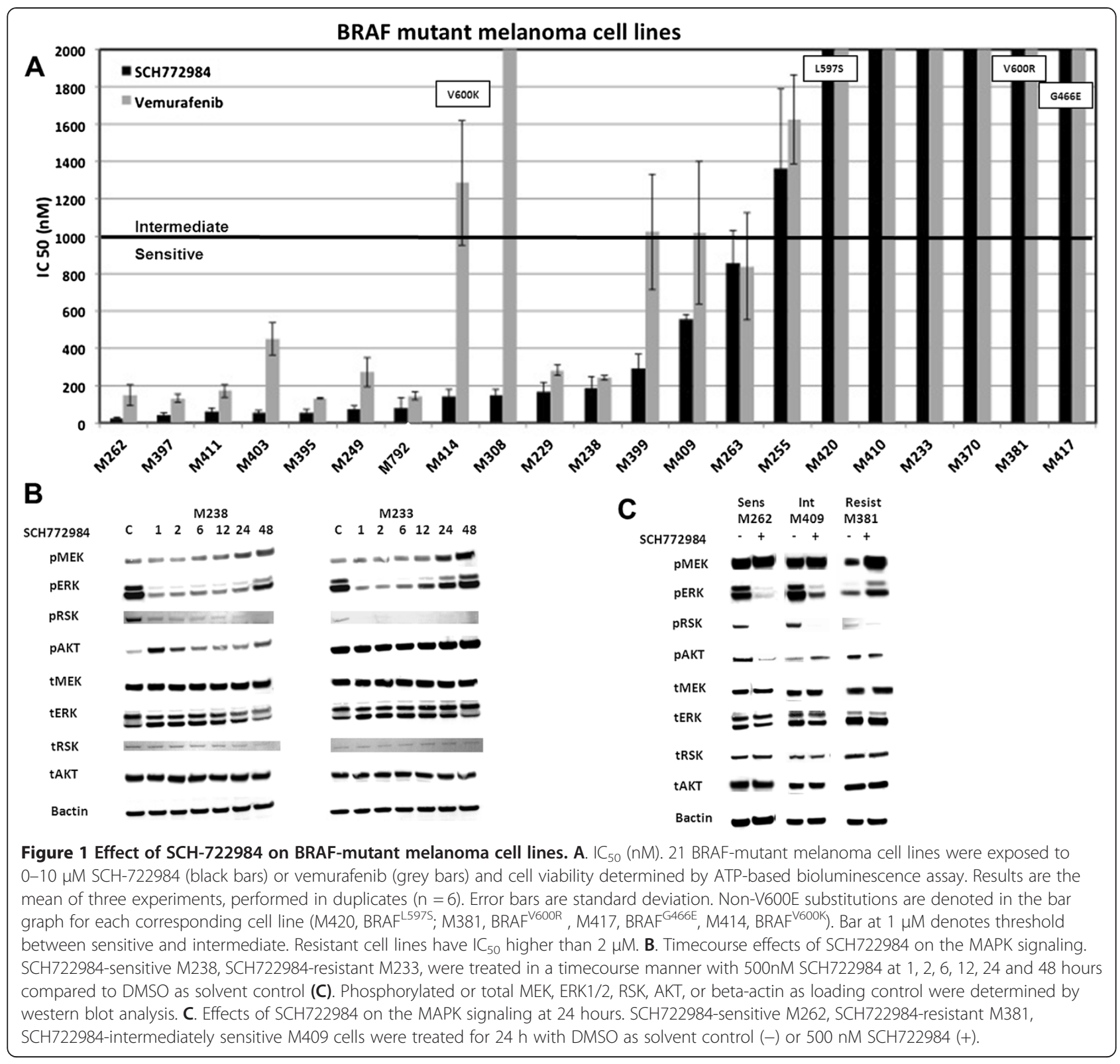

melanoma cell line (Figure 1B). For both M233 and M238, treatment with 500nM SCH772984 inhibited pRSK, a known ERK1/2 downstream target, as well as pERK1/2 itself. For the resistant M233, the MAPK inhibition was strong as early as 1 hour post treatment, with decreased pERK and near-complete disappearance of pRSK. However, between 12 and 24 hours we observe a rebound in the pathway with a return to baseline pERK1/2 levels and an induction in pMEK above baseline levels by 24 hours. Little change in pAKT was seen at any timepoint up to 24 hours, though a mild induction was seen at 48 hours. For the sensitive M238, pRSK levels also decreased as early as 1 hour and levels continued to decrease thereafter. Meanwhile, pERK1/2 remained suppressed through 24 hours. By 48 hours, pERK1/2 levels increased, though at reduced levels compared to baseline. Concomitant with this, pMEK levels remained unchanged until 24 hours and increased further by 48 hours. Regarding pAKT, an early induction at 1 hour occurred, followed by decreases thereafter though never becoming completely suppressed even at 48 hours. In both cell lines, pRSK remained blocked at all timepoints, demonstrating ongoing, potent inhibition of ERK1/2 activity by SCH772984. These data supports that the distinction between sensitive and resistant cell lines could be best made based on pERK recovery at 24 hours, as recovery of the feedback loop that restores MAPK activity occurred by 24 hours in the resistant cell line whereas the sensitive cell line required longer than 24 hours. Therefore, for subsequent analyses, we selected 24 hours as the optimal timepoint to compare signaling in our cell lines. 
As shown in Figure $1 C$, three $B R A F$ mutant cell lines representative of the different sensitivity groups to $\mathrm{SCH} 772984$ were profiled in terms of downstream signaling inhibition at 24 hours: a highly sensitive cell line (M262, $\left.B R A F^{V 600 E}\right)$, an intermediately sensitive cell line (M409, $\left.B R A F^{V 600 E}\right)$, and a resistant cell line $\left(\mathrm{M} 381, B R A F^{V 600 R}\right)$. For M262, treatment with $\mathrm{SCH} 772984$ resulted in disappearance of pRSK, disappearance of pERK1/2, decrease in pAKT, and slight induction of pMEK at 24 hours. M409 had a similar cell signaling profile as M262, consistent with its modest sensitivity. For M381induction of pMEK and pERK1/2 were seen with no change in pRSK at $24 \mathrm{~h}$.

To determine the effect of SCH772984 on the PI3K/AKT pathway, we first evaluated the baseline pAKT levels for a group of cell lines (Additional file 2: Figure S2). We found a weak correlation with the activity of the PI3K/AKT pathway and sensitivity to SCH772984 for BRAF mutants. For example, M238 and M409 are two clear examples of cell lines with low levels of pAKT related to sensitivity to SCH772984. For both of them, ERK inhibition with SCH772984 was accompanied by an upregulation of pAKT levels even at 24 hours treatment (Figure 1B). M233 was among the resistant $B R A F^{V 600 E}$ melanoma cell lines, which appeared to have increased pAKT at baseline compared to other BRAF mutant cell lines. Consistent with this, M233 is a PTEN null cell line and has a concomitant AKT1 amplification [31]. After treatment with SCH772984 (Figure 1B), these levels stay constant, indicating that dual inhibition with SCH772984 and AKT/mTOR inhibitors may be a useful strategy. In contrast, M262 is an AKT1 amplified cell line [31] with high sensitivity to SCH772984 and vemurafenib. Treatment of M262 with SCH772984 reduced both pERK1/2 and pAKT levels, indicating blockade of the MAPK pathway and PI3K/AKT pathway at the same time (Figure $1 \mathrm{C}$ ). In general, the presence of $A K T 1$ or $A K T 2$ amplification did not preclude sensitivity to SCH772984, as three of five such cell lines were highly sensitive to SCH772984 (M229, M249, and M262), one was intermediately sensitive (M255), and M233 and M308 were resistant (Figure 1A).

Given high baseline pAKT levels were seen in some cells resistant to ERK inhibition (Additional file 2: Figure S2) and the persistence of pAKT activity with $\mathrm{SCH} 722984$ treatment, we evaluated the effect of SCH772984 in combination with the AKT inhibitor MK-2206 or the mTOR inhibitor MK-8669. The addition of either the AKTi or mTORi always resulted in more potent cell growth inhibition compared to ERKi alone (Additional file 3: Figures S3A and 3B). Combining SCH772984 with the mTOR inhibitor MK-8669 was particularly synergistic. For BRAF-mutant cell line M233, both combinations resulted in more complete decrease in pERK compared to treatment with SCH772984 alone. Despite the improved inhibition of the MAPK pathway, the levels of PAKT were largely unaffected by the addition of MK-2206 or MK-8669 (Additional file 3: Figure S3C).

\section{Potent SCH772984-mediated ERK inhibition in BRAF-wild type melanoma cell lines}

Currently, there is no effective targeted therapy for $B R A F$ wild-type melanoma, which comprises $50 \%$ of all melanomas. Fourteen NRAS mutant melanoma and seven cells lines with wild-type BRAF and NRAS were evaluated for SCH772984 sensitivity. As shown in Figure 2A, while all NRAS-mutant cell lines were resistant to vemurafenib, 11 of 14 were highly sensitive to SCH772984 ( $\left.\mathrm{IC}_{50}<1 \mu \mathrm{M}\right)$. Across the 11 NRAS sensitive cell lines, two of them were Q61L (M296 and M311), four were Q61K (M408, Sbcl2, WM1366, M245 and M244), one was Q61H (M243) and three were Q61R (SKMEL173, M296 and M412a). Interestingly, the three cell lines with IC50 > 1uM (M202, M207 and M318) were exclusively NRAS Q61L mutated. Sensitivity to trametinib are shown in Additional file 4: Figures S4A and 4B for NRAS-mutant and wild-type melanoma cell lines, respectively. Consistent with the profile for sensitive cell lines, treatment with SCH772984 for the sensitive M408 resulted in decreased pRSK, disappearance of pERK1/2, and slight induction of pMEK, with no change in total RSK, MEK, ERK $1 / 2$, or AKT. For the resistant M202, a modest induction of pMEK with some decrease in pERK and pRSK was observed at 24 hours (Figure 2B). Treatment with SCH772984 resulted in upregulation of pAKT levels for M408 and WM1366 (Additional file 3: Figure S3C). Consistent with the synergistic growth inhibition seen with combining SCH772984 and either MK-2206 or MK-8669, pAKT levels were abrogated with the addition of MK2206 (AKT inhibitor) and MK-8669 (mTOR inhibitor) (Additional file 3: Figure S3A-C).

For $B R A F$ and NRAS wild-type melanoma cell lines, all seven were sensitive to ERK inhibition, with six of seven highly sensitive to SCH772984 (Figure 3A), including M418, which is a KRAS ${ }^{G 12 A}$ mutant. Consistent with this, treatment with SCH772984 in the highly sensitive M285 line resulted in complete disappearance of pRSK, decreased pERK1/2 and induction of pMEK. M257, which is intermediately sensitive to SCH722984, had near-complete disappearance of pRSK, though pERK1/2 was slightly induced at 24 hours. Phospho-MEK was also induced in treated cells. No changes in pAKT with SCH772984 were seen in either M285 or M257 (Figure 3B). These data indicate that $\mathrm{SCH} 772984$ may be effective against a majority of $B R A F$ wild-type cell lines including $N R A S$ mutants and $B R A F / N R A S$ wild-type melanoma cell lines which remain dependent on the MAPK pathway for continued growth. 


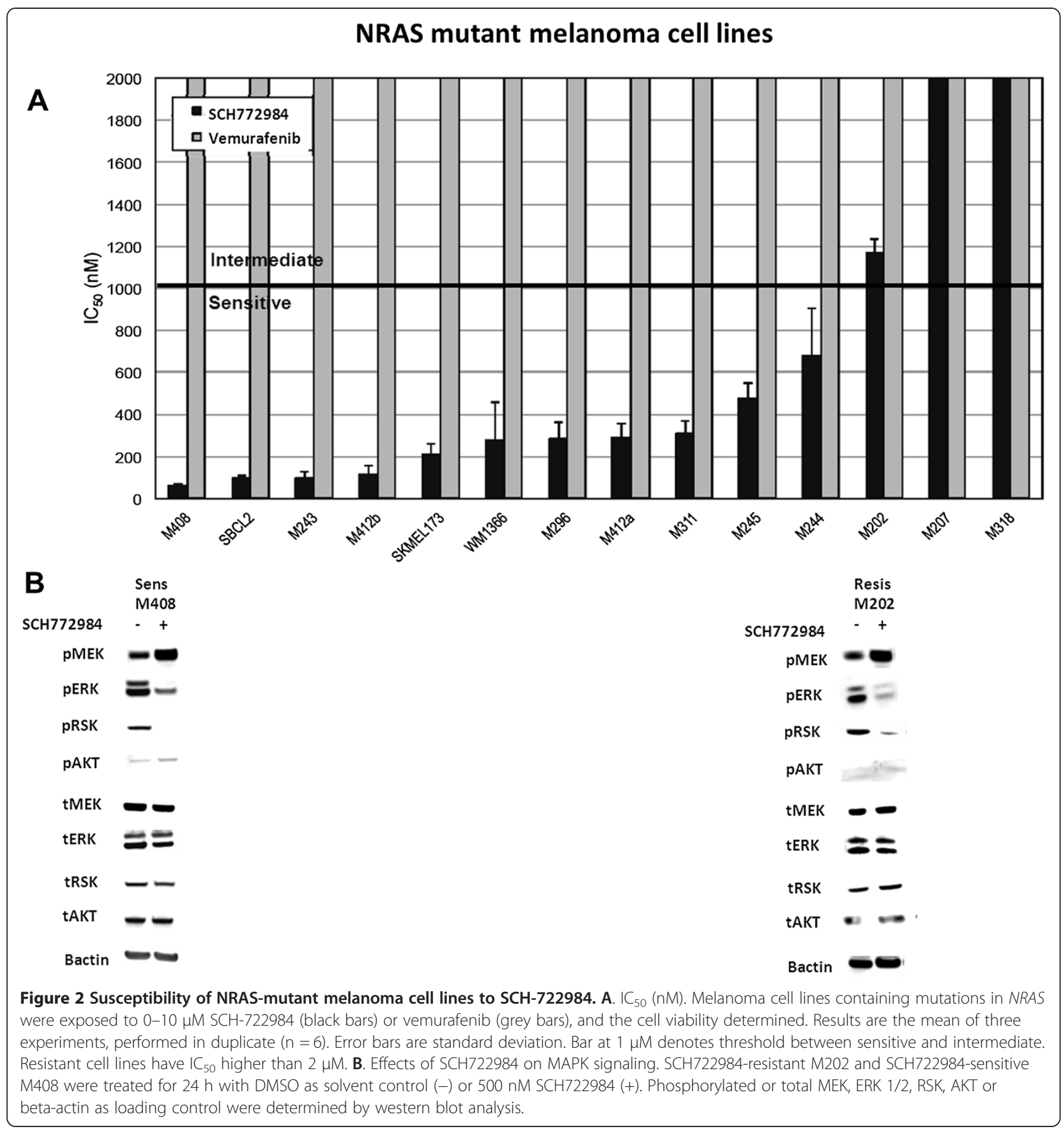

SCH722984 is effective in BRAF-mutant melanoma with acquired vemurafenib-resistance

The $\mathrm{IC}_{50}$ of $\mathrm{SCH} 722984$ or vemurafenib was next determined in eight $B R A F$-mutant vemurafenib-resistant melanoma cell lines (Figure 4A). M376 and M398, two $B R A F / N R A S$ double mutant cell lines derived from the same patient tumors, were highly sensitive to SCH722984, despite high resistance to vemurafenib. M376 is a spontaneously arising double mutant, whereas M398 was established from tumor from the same patient upon progression on vemurafenib. Similar to their isogenic parental cell lines, potent growth inhibition with SCH772984 was also seen for three $B R A F^{V 600 E}$ mutant melanoma cell lines with in vitro-derived vemurafenib resistance (polyclonal population): M395AR, M397AR, and M249AR4. Previously data demonstrated that these cell lines reactivate the MAPK pathway via generation of BRAF splice variants (M395AR and M397AR) [7,24], or via secondary NRAS mutation (M249AR4) [6]. In contrast, M229AR9, M238AR2 and M409AR1 remained highly 


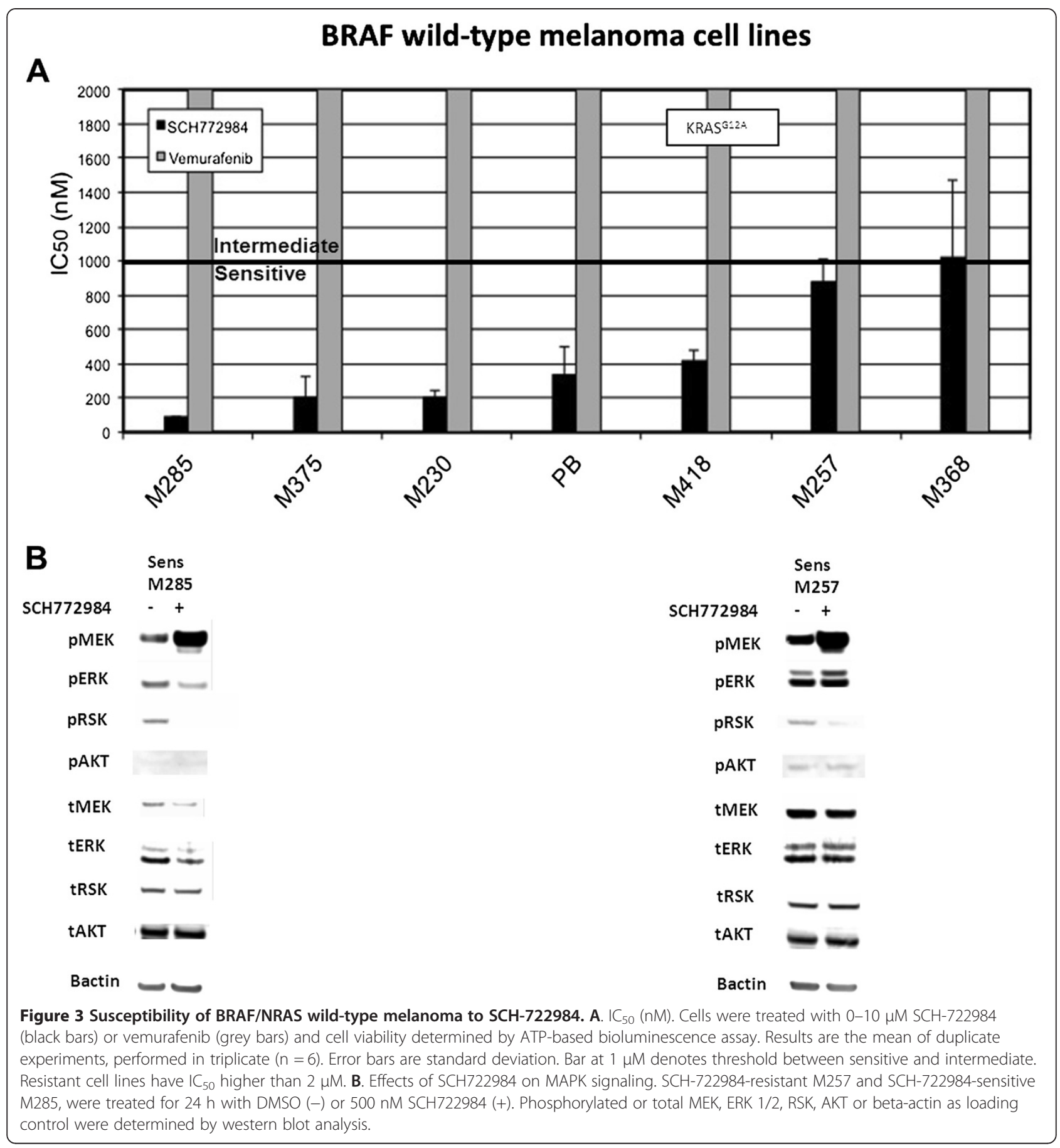

resistant to SCH722984 with IC50s >2uM. For M229AR9 and M238AR2 upregulation of RTK is the mechanism of vemurafenib resistance [6]. The mechanism of resistance for M409AR is unknown at this time, and studies are ongoing to delineate the mechanism underlying BRAFi-resistance.

Consistent with the signaling for other sensitive cell lines, all three BRAF/NRAS double mutants (M376, M398, M249AR4) displayed decreased pRSK and pERK1/2 at 24 hours with no detectable change in pMEK. In the paired parental and acquired-resistance cell lines, treatment of the parental cell lines (M397, M249, M229, M238 and M409) with SCH722984 resulted in disappearance of pRSK, decrease in pERK1/2. Interestingly, we observed again upregulation of pAKT levels after treatment with SCH772984 in M398, M376, M397AR, M249AR4, and M409AR1, suggesting a rapid upregulation of the PI3K/AKT/mTOR pathway. This suggests that dual inhibition with SCH772984 and an AKT or mTOR inhibitor may result in more potent 


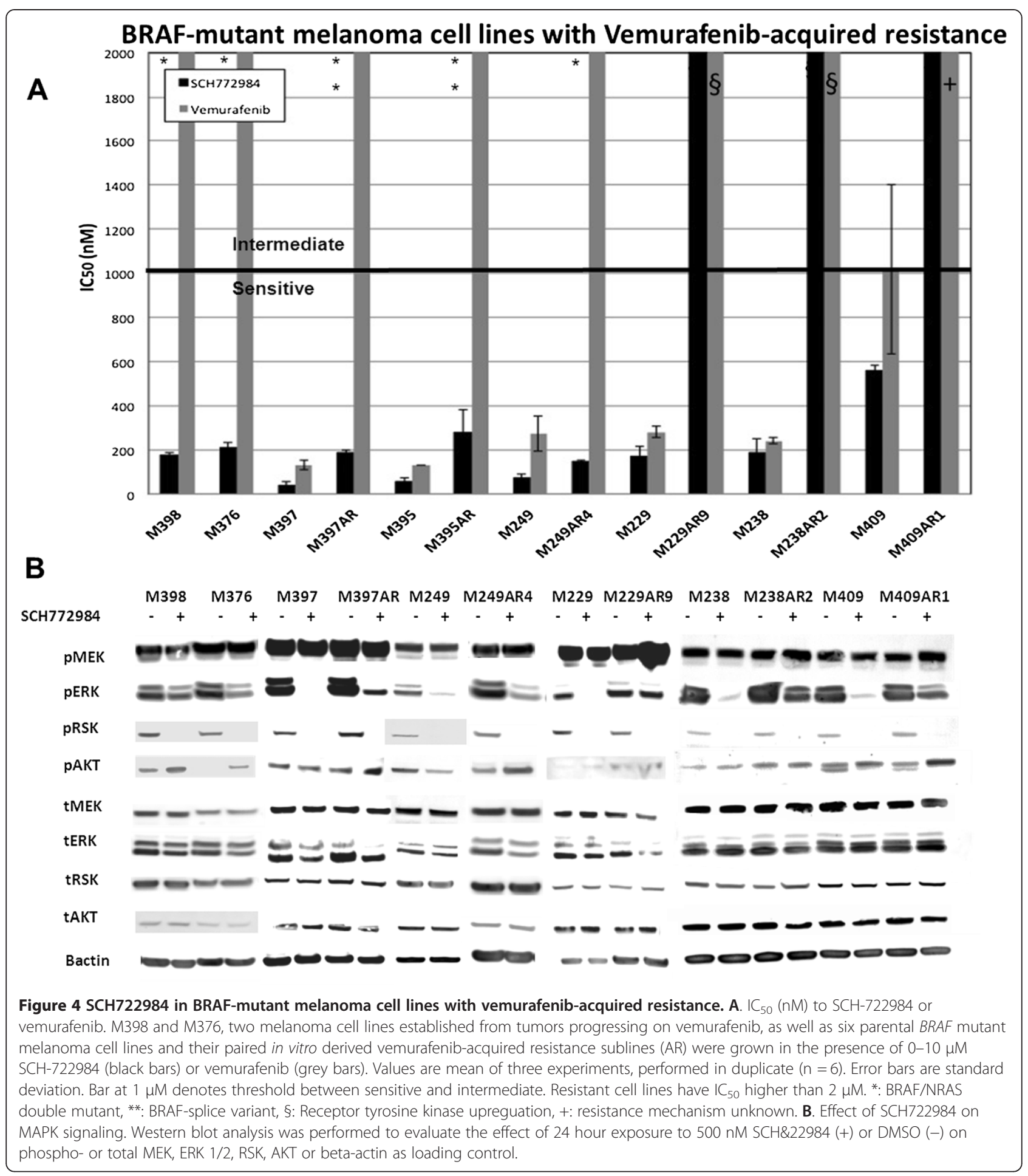

growth inhibition. For M397AR and M249AR4, the disappearance of pERK was robust. In contrast, for the resistant M229AR9, M238AR2 and M409AR1, though treatment with SCH772984 resulted in disappearance of pRSK, pMEK appeared to be induced and pERK1/2 remained almost unchanged (Figure 4B).
Synergistic inhibition with combination BRAF and ERK inhibition

We next determined whether combining BRAF and ERK inhibition could result in synergistic inhibition by dual MAPK pathway inhibition. Treatment of M238 and M792, two $B R A F^{V 600 E}$-mutant melanoma cell lines highly sensitive 
to singular treatment with vemurafenib and SCH772984, with equimolar concentrations of combined vemurafenib and SCH772984 treatment resulted in potent synergistic growth inhibition with $\mathrm{IC}_{50}$ of $10 \mathrm{nM}$ (Figure $5 \mathrm{~A}, 5 \mathrm{~B}$ ). Combining vemurafenib with $\mathrm{SCH} 772984$ resulted in a more profound decrease in pRSK and pERK for the highly sensitive M262 and M792 lines compared to untreated controls or treatment with either agent alone. M262 resulted in decreased pAKT levels after all three treatments. For M308, which is resistant to vemurafenib and sensitive to SCH772984, as pRSK was already completely absent with treatment with SCH772984 alone, no additional effect of the combination was apparent (Figure 5C). Interestingly, at 24 hours post treatment, induction of pMEK and pERK was already seen, indicating rapid feedback recovery for M308, despite its sensitivity to SCH772984. A slight decrease in pERK1/2 was seen with SCH772984 treatment, with a compensatory increase in pMEK. The generally more resistant M308 and M370 lines, in contrast to the generally more sensitive M262 and M792 lines, did not show a decrease in PMEK when combining the two drugs, which seems to be due to the lack of activity of vemurafenib in these resistant cells. No additive effect from the dual upstream blockade could be noticed in the immediate downstream targets, indicating that the pathway remained active (Figure 5C). All cell lines sensitive to BRAFi were also sensitive to the combination. Four intermediately sensitive cell lines to BRAFi became highly sensitive to the combination, with improved pathway inhibition compared to ERK inhibition alone in all cases. More importantly, highly resistant cell lines to BRAFi became sensitive (M420, M308, M410) or intermediately sensitive (M417, M370, M229AR, M409AR1) to the combination. Three remained resistant but with a slightly improved $\mathrm{IC}_{50}$. C.I.s demonstrated synergy with combined BRAF and ERK inhibition for all cell lines except M308, in which dual treatment with vemurafenib and SCH772984 is only additive (Figure 5D).

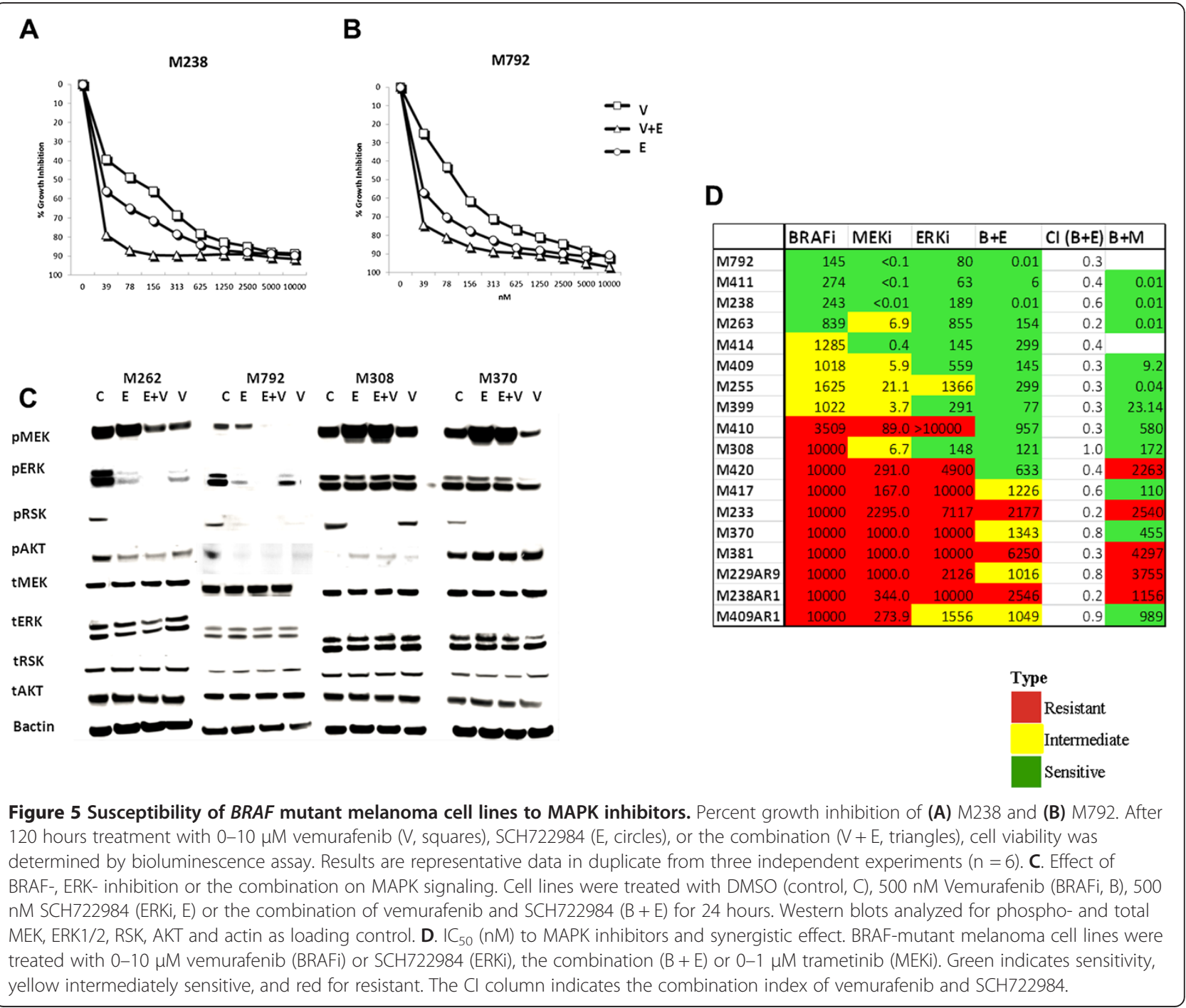


We next examined whether cells inherently resistant to BRAFi could be sensitive to a MEK inhibitor (MEKi) or ERKi. Sensitivity of BRAF mutant melanoma cell lines to BRAFi predicted sensitivity to MEK and ERK inhibitors. Furthermore, 10 cell lines inherently resistant to BRAFi were often sensitive to MEK and ERK inhibition, and cell lines resistant to BRAFi or MEKi were relatively more sensitive to SCH722984. Indeed, combining BRAF with ERK inhibition potently decreased the equimolar $\mathrm{IC}_{50}$ of all cell lines and resulted in synergy in all but one case (M308), including M255, M399 and M420, which are completely resistant to individual inhibitors (Figure 5D). Because the combination on BRAF combined with MEK inhibition is currently FDA approved for $B R A F^{V 600}$ mutant melanoma, we also determined the $\mathrm{IC}_{50}$ for the combination of vemurafenib and trametinib. The results showed potent growth inhibition and synergy in all cell lines. Sensitivity to the vemurafenib + trametinib combination generally overlapped with sensitivity to the vemurafenib + SCH722984 combination (Figure 5D), consistent with the idea that both combinations cause dual MAPK blockade. The growth curves for the vemurafenib + trametinib combinations are shown in Additional file 5: Figure S5.

\section{Effects of MAPK pathway inhibition on cell cycle progression and apoptosis}

To determine the effect of BRAF or ERK inhibition on cell cycle progression and apoptosis, cells were treated with SCH772984, alone or in combination with vemurafenib for 48 hours then stained with DAPI and intracellularly for cleaved PARP and analyzed by flow cytometry. Treatment with either of these two inhibitors resulted in an increase in the sub-G0 population, the G1 population, as well as an increase in cleaved PARP levels which indicates apoptotic cells (Figure 6A). A modest increase of 3-10\% was seen in the sub-G0 population for all cell lines treated with vemurafenib, SCH772984 or the combination. The amount of subG1 increase did not correlate with sensitivity or resistance to the MAPK pathway inhibitors. In contrast, for the G0-G1 populations, there was a correlation with sensitivity, with an up to $40 \%$ increase in G0G1 population seen in the sensitive cell lines M238 and M792, while the resistant cell lines M233 and M299 demonstrated only a $10 \%$ increase in the G0-G1 population for the combination treatment. Concomitant with the increase in G0-G1, a decreased proportion of cells were observed in S-phase, with the largest decreases of over 20\% seen in the sensitive cell lines M792 and M238 (Figure 6B). Treatment of the sensitive cell lines, M238 and M792, with SCH772984 alone or in combination with vemurafenib resulted in a dramatic increase in cleaved PARP reaching induced percentages around 40-50\%. In comparison, the resistant cell lines (M233 and M299) had cleaved PARP at 20-25\% (Figure 6C). With the exception of M299, a statistically significant increase in cleaved PARP was seen in all cell lines treated with SCH772984, or the combination of SCH772984 and vemurafenib, compared to vemurafenib alone. Combinatorial treatment offered a statistically significant increase in cleaved PARP compared to vemurafenib alone in all cell lines (20\% increase in sensitive cell lines and 10\% increase in resistant cell lines compared to vemurafenib alone). However only a trend towards increased cleaved PARP fractions was observed comparing combinatorial treatment with SCH772984 alone without reaching statistical significance.

To address whether there are differences in MEK inhibition or ERK inhibition on apoptosis, we performed cell cycle analysis on three melanoma cell lines with distinct sensitivity profile to SCH772984: M263 (sensitive), M255 (intermediately sensitive) and M370 (resistant). All three cell lines demonstrated good synergy for the combination of vemurafenib and SCH772984. Cell lines treated with $\mathrm{SCH} 772984$ or the combination of vemurafenib + SCH772984 had the highest levels of cleaved PARP. In comparison, trametinib, did not induce the same levels of apoptosis in any case. In terms of effects on the cell cycle, G0-G1 arrest was maximally induced by ERK inhibition also (Additional file 6: Figure S6). This data support the potent activity of SCH772984 both as a single agent and in combination.

\section{Combining BRAF and ERK inhibition delays the development of resistance}

Given the potent synergistic inhibition seen when combining vemurafenib and SCH772984, we hypothesized that chronic exposure to dual inhibition would significantly delay the development of resistance compared to either single agent alone. To test this hypothesis, long term cultures were established in 96-well plates to allow both qualitative and quantitative assessment of the effect of each drug alone or their combination on M238 and M792, which are highly sensitive to both inhibitors and for which dual therapy was highly synergistic (Figure 7A). Treatment with 500nM vemurafenib initially suppressed growth of M238 and M792, however, by 42 days of treatment, several wells were confluent and cells had normal morphology, indicating development of BRAFi-resistance. In contrast, very few cells were seen in plates treated with ERKi alone or in combination at 42 days (Figure 7B). For ERKi-treated M792 plates, confluent wells were not seen until 84 days. When cell viability was quantified at day 44 for BRAFi-treated cells, over $90 \%$ of the wells had $>10,000$ viable cells. In contrast, many fewer viable cells were seen for M792 treated with ERKi alone or in combination with BRAFi measured at day 84 . Only $20 \%$ of the wells treated with ERKi alone and $<5 \%$ of wells treated with the combination had $>10,000$ cells (Figure 7C). For M238, similar data were seen, though in this case, treatment with $500 \mathrm{nM}$ 


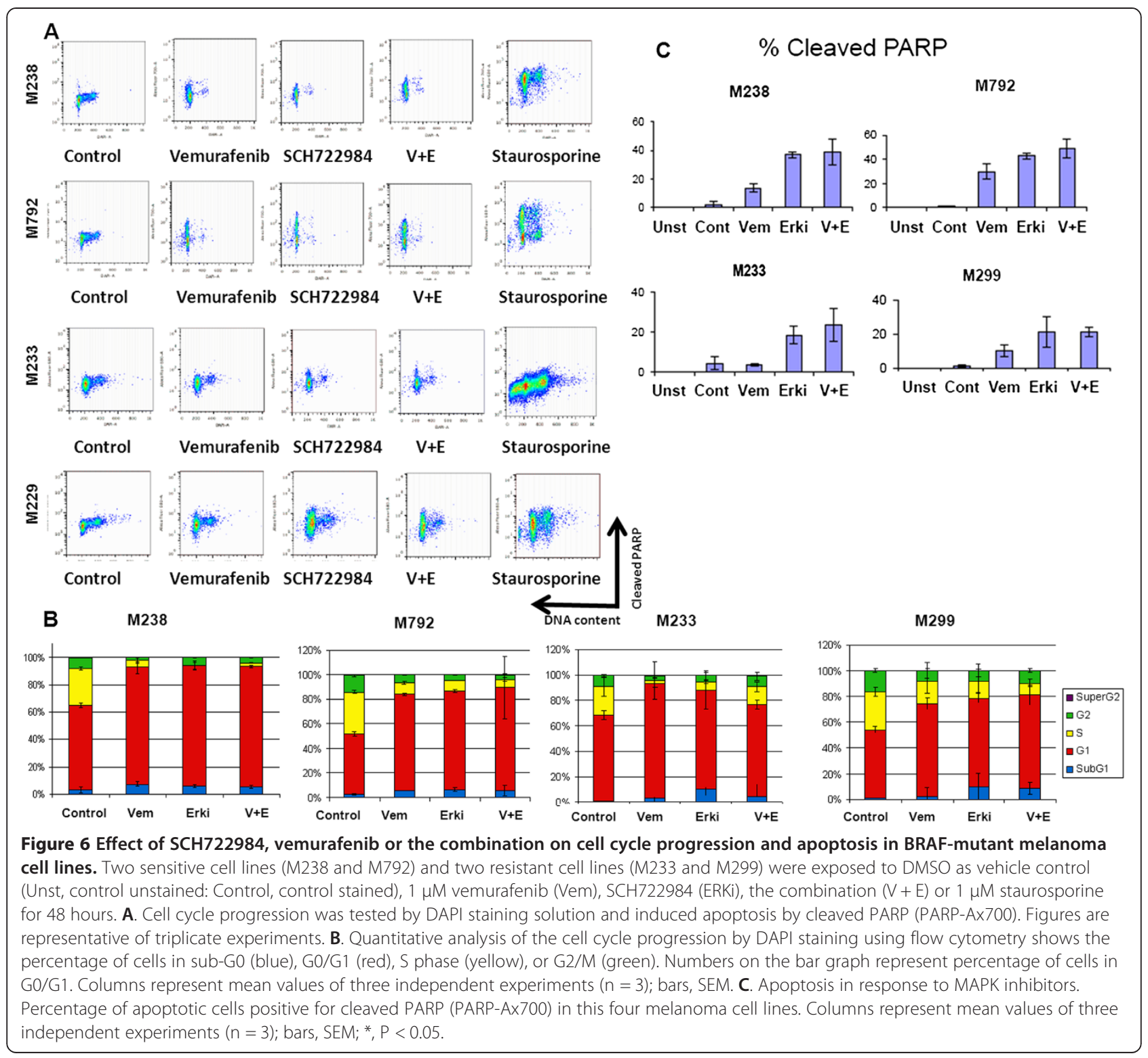

ERKi alone delayed the development of resistance until 140 days. Most strikingly, for M238, 280 days, twice that for SCH772984 alone, were required for resistance to the combination of vemurafenib and SCH772984 to develop (Figure 7D). Taken together, these data provide preliminary in vitro evidence that $\mathrm{SCH} 772984$ may more potently and more durably inhibit $B R A F$-mutant melanoma compared to single agent vemurafenib, and that the combination of BRAF and ERK inhibition results in better inhibition than either alone. These data are intriguing and should be further validated in vivo.

\section{Discussion}

Our work reports the potent activity of SCH772984 against a large panel of well-characterized melanoma cell lines. SCH772984 is highly active amongst $B R A F$-mutant, $N R A S$-mutant, double mutant and double wild-type melanoma cell lines, and this drug potently inhibited some lines with innate resistance or acquired resistance to vemurafenib. The efficacy of SCH772984 in NRAS-mutant and double wild-type melanoma was also striking with the majority being highly sensitive.

Previously published reports have documented promising preclinical activity of ERK inhibition in BRAFi or MEKi resistant cell line models [30,32,33]. Our data are consistent with the work of Carlino et al., who demonstrated that SCH772984 induced cell death for all sensitive cell lines. SCH772984 also resulted in growth inhibition of only melanoma cell lines with MAPK-dependent mechanisms of BRAFi-resistance, and not those with RTK upregulation 


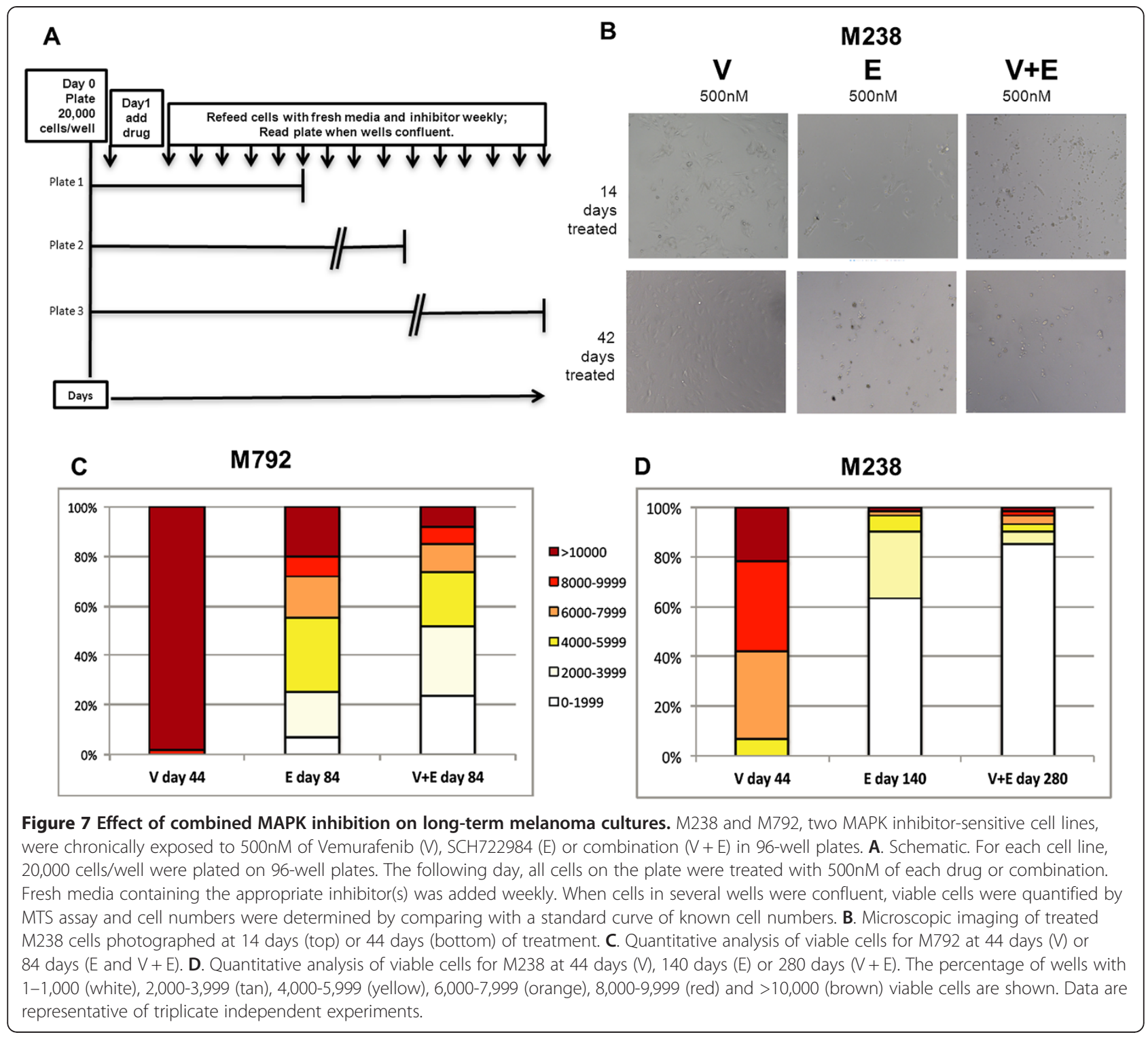

as the mechanism of BRAFi resistance. Furthermore, their work demonstrated that trametinib less completely inhibited MAPK signaling compared to inhibition with VX-11e, an ERKi tool compound [33]. Since resistance to BRAFi or MEKi is highly dominated by the reactivation of the MAPK pathway (acquisition of $R A S$ mutations, $B R A F^{V 600}$ amplifications, $M E K$ mutations, $B R A F^{V 600 E}$ amplification or the $\triangle 2-8$ BRAF splice variant [30] or secondary RTK overexpression), SCH772984 is a promising strategy to delay or revert resistance and has demonstrated activity in our BRAFi-resistant melanoma cell lines with reactivation of the MAPK pathway mechanism of resistance. Unfortunately resistance to SCH772984 may appear and resistance mechanisms will likely differ from those characterized thus far. We observed that increased pAKT levels at baseline levels were tightly correlated with intrinsic resistance to
SCH772984 in the BRAF- mutant melanoma cell lines. Little to no pAKT activity was found in two NRAS mutant or two double wild type cell lines. Indeed, Carlino et al. hypothesize consistently in their work that pAKT levels for BRAF mutant melanoma cells may play a key role in resistance. SCH772984 is unique, having both ATP-competitive and non-competitive properties, leading to suppression of both the downstream factors of and pERK1/2 itself which was observed in short term treatment (less than 12 hours) of cell lines tested in this study. This was further elucidated by Morris et al., who demonstrated that the inhibition of pERK1/2 is not just mediated by inhibitor binding to MEK. Instead, they hypothesize that binding of SCH772984 to ERK protein not only prevents ATP binding and therefore phosphorylation of downstream targets like RSK, but that ERK binding 
also inhibits the ability of MEK protein to access and phosphorylate ERK1 at threonine 202/tyrosine 204 and ERK2 at threonine 185/tyrosine 187 [30]. Additionally, the data herein underscore the importance of MAPK feedback loops in sensitivity to SCH772984 given the consistent finding that cell lines resistant to SCH772984 are able to rapidly recover pMEK and pERK activity, while those sensitive to $\mathrm{SCH} 772984$ have delayed ability to do so. One notable exception to this signaling pattern is M308, which demonstrated a rapid recovery of MAPK activity even at 24 hours after ERKi-treatment, despite its sensitivity to SCH772984. In work ongoing in the lab, among 5 BRAF-mutant cell lines sensitive to SCH772984, M308 was the only cell line to develop resistant subclones after 2 months of chronic exposure to SCH772984 (data not shown). This indicates that feedback recovery may be an important predictor of development of acquired resistance to ERKi. Given that pRSK remains suppressed at all time points tested, reactivation of the MAPK pathway may allow signaling through other ERK downstream targets, such as cyclin D1.

Previous data supports that pERK signaling recovers rapidly after vemurafenib treatment, yet cells remain growth arrested [16]. Besides the synergistic effect of vemurafenib and $\mathrm{SCH} 772984$, our data supports a strong induction of apoptosis with the ERKi compared to the BRAFi alone. This should encourage combined therapy approaches to strengthen the therapy against feedback loops reactivated after single point blockade. The strategic aspect of ERK inhibition both blocking downstream in the MAPK pathway and blocking the cross-talk with Pi3K/AKT can support a rationale to combine inhibition of both pathways.

Both the non-competitive inhibitory properties of SCH772984 and its ability to cause reactivation of the MAPK pathway may explain the synergy seen with combination BRAF- and ERK-inhibition in the vast majority of $B R A F$-mutant melanoma. It may also explain the dramatic delay in development of resistance seen with BRAF-inhibitor in BRAF-mutant melanoma tested in this study. At first glance, the idea of inhibiting two points in the same pathway may seem redundant. However, as shown herein, the dual inhibition approach may be a good strategy to control the feedback loop reactivation that occurs with singular treatment with ERKi. Carlino et al. [33] , recently published that combinatorial blockade with relatively high concentrations of the ERKi, Vx-11e $(10 \mu \mathrm{M})$ and PI3K/AKT inhibitor BEZ235 $(2 \mu \mathrm{M})$ more completely induced cell death in BRAF-inhibitor resistance melanoma cell lines compared to the combination of trametinib $(10 \mathrm{nM})$ and BEZ235. Consistent with this, Lassen et al. recently demonstrated that MAPK and PI3K pathway dual inhibition can effectively inhibit melanoma cells [34]. Given the likely differences in toxicity profile of both combinatorial approaches, clinical evaluation of both BRAFi/ERKi and
ERKi/PI3Ki should be pursued. Further investigations regarding the mechanisms underlying both primary and acquired resistance to SCH772984 are ongoing.

\section{Conclusions}

Currently, at least two ERK inhibitors are in phase I studies, including MK8353, a clinical grade analog of SCH772984, and BVD-523. Our preclinical findings demonstrate the ability of SCH772984 to inhibit the majority of melanoma cell lines tested. Over $50 \%$ of all melanoma patients are non-BRAF mutated, with NRASmutant and double wild-type comprising $15-20 \%$ and $40 \%$ of melanoma patients, respectively. As there are currently no FDA-approved targeted therapies for these non-BRAF mutated melanoma, these data provide intriguing preclinical basis for further development and testing of ERK inhibitors for these melanoma subtypes, as well as for combinatorial therapy with BRAF and ERK inhibitors in BRAF-mutant melanoma. Therefore, ERK inhibitors hold much promise to augment the armamentarium of effective targeted therapies for melanoma, regardless of $B R A F$ mutational status and irrespective of sensitivity to BRAF inhibitors.

\section{Materials and methods \\ Reagents and cell lines}

SCH722984 (Erk inhibitor), MK-2206 (AKT inhibitor) and MK-8669 (mTOR inhibitor) were obtained through a materials transfer agreement with Merck Sharp \& Dohme Corp. (Whitehouse Station, New Jersey). Vemurafenib and trametinib were commercially purchased (Selleck Chemicals, Houston, TX). All drugs were reconstituted in $100 \%$ dimethyl sulfoxide (DMSO) to a final concentration of $10 \mathrm{mM}$. With the exception of Sbcl2, SKMel173, WM1366, which were obtained from Dr. Roger S. Lo (UCLA), all other human melanoma cell lines were established from patient biopsies under UCLA- IRB \#0208-067, as previously described [31]. Cells were cultured in RPMI 1640 with L-glutamine (Mediatech, Inc, Manassas, VA), $10 \%$ fetal bovine serum (FBS, Omega Scientific, Tarzana, CA), and $1 \%$ penicillin, streptomycin and fungizone (PSF, Omega Scientific). Cultures were incubated in a watersaturated incubator at $37^{\circ} \mathrm{C}$ with $5 \% \mathrm{CO}_{2}$.

\section{Cell viability}

All cell lines were treated in duplicates with $0-10 \mu \mathrm{M}$ of SCH722984, vemurafenib and trametinib alone or in combination and constant amount of DMSO for all the conditions. After incubation for 72-120 hours, the cell viability was determined using CellTiter-Glo Luminescent Cell Viability Assay (Promega, Madison, WI), an ATPbased bioluminescent assay, as per manufacturer's instructions. Each experiment was repeated independently at least 3 times. 
For long-term culture experiments, M238 and M792 cell lines were plated at 20,000 cells per well in 96-well plates and chronically exposed to $500 \mathrm{nM}$ of vemurafenib, SCH722984 or the combination. Cells were re-fed with fresh media containing the appropriate inhibitor(s) weekly. Pictures were taken weekly to document visual differences in between conditions. Plates were considered for cell viability reading with [3-(4,5-dimethylthiazol-2-yl)-5(3-carboxymethoxyphenyl)-2-(4-sulfophenyl)-2H-tetrazolium (MTS) (Promega) as previously described [31] when several wells appeared visually to be $>90 \%$ confluent. The number of viable cells in each well was determined based on a standard curve of known cell numbers. Each condition was repeated in triplicate independent experiments.

\section{Western blotting}

All melanoma cells were washed with ice-cold phosphate buffered saline (PBS) twice and lysed with RIPA buffer containing phosphatase and protease inhibitors (all from Sigma Aldrich, St. Louis, MO). Protein extracts were separated with SDS-PAGE in 4-12\% tris-glycine gels and transferred to immun-blot PVDF membrane. After blocking for 1 hour in PBS containing 0.1\% Tween 20 and $5 \%$ nonfat milk or $5 \%$ bovine serum albumin (BSA) in PBS, the membrane was exposed to various primary antibodies overnight, followed by secondary antibodies conjugated to horseradish peroxidase. ECL-Plus kit (Amersham Biosciences Co, Piscataway, NJ) was used to check immunoreactivity and blots were scanned using a Typhoon scanner (Amersham Biosciences Co.). Primary antibodies included pERK Thr202/Tyr204, total ERK, pMEK Ser217/221, total MEK, pAKT Ser473, total AKT, pRSK, total RSK, beta-actin (all from Cell Signaling Technology, Danvers, MA).

\section{Cell-cycle analysis and assessment of apoptosis by flow cytometry}

M238, M792, M299 and M233 melanoma cell lines were incubated with $1 \mu \mathrm{M}$ of DMSO as vehicle control, vemurafenib, SCH772984, or the combination for 48 hours. Cells were collected and fixed with BD Cytofix/Cytoperm (BD Biosciences, San Jose, CA), washed with BD Perm/ Wash Buffer $1 \mathrm{x}$ and resuspended in $500 \mu \mathrm{L}$ of 4,6 diamidino-2-phenylindole (DAPI) solution at a final concentration of $2 \mathrm{mg} / \mathrm{mL}, 0.001 \%$ Nonident P-40, and $1 \%$ BSA in PBS (Sigma-Aldrich). Analysis was performed after acquiring 12,000 cellular events in G0-G1 gate per sample. For analysis of apoptosis, cells were checked at the level of cleaved poly [ADP-ribose] polymerase (PARP). After fixation and permeabilization as described above, cells were stained with anti-PARP-Alexafluor700 antibody (clone F21-852; BD Biosciences). A minimum of 12,000 cellular events per sample were collected by flow cytometry. All flow cytometry experiments were carried out using an LSRII (BD Biosciences), using biexponential axes. Data were analyzed using FlowJo (Tree Star, Inc, Ashland, OR).

\section{Statistical analysis}

Data analysis was performed with Microsoft Excel and GraphPad Prism to determine the 50\% inhibition concentration $\left(\mathrm{IC}_{50}\right)$. Synergistic, additive or antagonistic effects of drug combinations were determined using Calcusyn software (version 2.0, Biosoft, Cambridge, United Kingdom) to determine the combination indices (C.I.) as previously described [35], where synergy is defined as C.I. $<1$, additivity C.I. $\simeq 1$, and antagonism is C.I. $>1$.

\section{Additional files}

Additional file 1: Figure S1. Effect of trametinib on BRAF mutant melanoma cell lines. $I_{50}(\mathrm{nM})$. Ninteen BRAF mutant melanoma cell lines were exposed to $0-1 \mu \mathrm{M}$ trametinib and cell viability determined by ATP-based bioluminescence assay (CellTiter-Glo, Promega). Results represent mean of duplicate assay performed in three independent experiments.

Additional file 2: Figure S2. Levels of PAKT across a group of BRAF, NRAS and double wild-type melanoma cell lines. 8 BRAF-mutant, 2 NRAS-mutant and 2 wild type melanoma cell lines in order of increasing $I_{50}$ sensitivities to SCH772984 were evaluated by Western Blot analysis for baseline PAKT levels.

Additional file 3: Figure S3. Effects of SCH722984 combined with MK-2206 (AKT inhibitor) and MK-8669 (mTOR inhibitor) in BRAF mutant cell lines. A. IC 50 S of SCH722984 alone or in combination with MK-2206 or

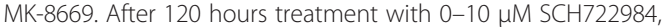
SCH722984+ MK-2206 or SCH722984+ MK-8669, cell viability was determined by bioluminescence assay. Results are representative data in duplicate from three independent experiments $(n=6)$. B. Percent growth inhibition for two BRAF-mutant melanoma cell lines (M233 and M411) and two NRAS-mutant cell lines (M409 and WM1366). After 120 hours treatment with 0-10 $\mu \mathrm{M}$ SCH772984 + MK2206 (ERKi + AKTi, squares), SCH722984 + MK-8669 (ERKi + mTORi, triangles), or the SCH772984 (ERKi, circles), cell viability was determined by bioluminescence assay. Results are representative data in duplicate from three independent experiments $(n=6)$. C. Effect ERK-inhibition alone or the combination with AKT/mTOR inhibitors on MAPK signaling. Cell lines were treated with DMSO (control, C), 1 uM SCH722984 (ERKi, E) or the combination of SCH722984+ MK-2206 and SCH722984+ MK-8669 at 1 uM for 24 hours. Western blots analyzed for phospho- and total ERK1/2, AKT and actin as loading control.

Additional file 4: Figure S4. Effect of trametinib on NRAS mutant and double wild type cell lines. IC50 (nM). 14 NRAS mutant and 7 double wild-type melanoma cell lines were exposed to 0-1 $\mu \mathrm{M}$ trametinib and cell viability was determined by ATP-based bioluminescence assay (CellTiter-Glo, Promega). Results represent mean of duplicate assay performed in three independent experiments.

Additional file 5: Figure S5. Combinatorial effect of Vemurafenib with SCH772984 or Trametinib. Percent growth inhibition of BRAF mutant cell lines. After 120 hours treatment with 0-10 $\mu \mathrm{M}$ vemurafenib (squares) combined with 0-10 uM SCH722984 (circles), or 0-10 $\mu \mathrm{M}$ vemurafenib combined with 0-1 $\mu \mathrm{M}$ trametinib, cell viability was determined by bioluminescence assay. Results are representative data in duplicate from two independent experiments $(n=6)$.

Additional file 6: Figure S6. Effect of SCH722984, vemurafenib or the combination on cell cycle progression and apoptosis in BRAF-mutant melanoma cell lines. A sensitive cell line (M263), intermediate sensitivity (M255) and resistant to SCH722984 (M370) were exposed to DMSO as vehicle control (ControL), $1 \mu \mathrm{M}$ vemurafenib (Vemurafenib), SCH722984 (ERKi), 50nM trametinib (Trametinib), the combination of $1 \mu \mathrm{M}$ vemurafenib $+1 \mu \mathrm{M} \mathrm{SCH722984}(\mathrm{V}+\mathrm{E})$ or the combination of $1 \mu \mathrm{Mvemurafenib}+50 \mathrm{nM}$ 
trametinib $(V+T)$ for 48 hours. A. Cell cycle progression example for M255 was tested by DAPI staining solution and induced apoptosis by cleaved PARP (PARP-Ax700). B. Apoptosis in response to MAPK inhibitors. Percentage of apoptotic cells positive for cleaved PARP (PARP-Ax700) in this three melanoma cell lines. B. Quantitative analysis of the cell cycle progression by DAPI staining using flow cytometry shows the percentage of cells in sub-G0, G0/G1, S phase, or G2/M.

\section{Abbreviations}

AR: Acquired resistant; C.I.: Combination Index; DAPI: 4,6-diamidino-2-phenylindole; DMSO: Dimethyl sulfoxide; FBS: Fetal bovine serum; $I_{50}$ : $50 \%$ inhibition concentration; IGF1R: Insulin growth factor receptor 1; MTS: [3-(4,5dimethylthiazol-2-yl)-5-(3-carboxymethoxyphenyl)-2-(4-sulfophenyl)-2Htetrazolium; $\mu \mathrm{M}$ : Micromolar; nM: Nanomolar; PARP: Poly [ADP-ribose] polymerase; PBS: Phosphate buffered saline; PDGFR : Platelet-derived growth factor beta; PSF: Penicillin, streptozocin, fungizone; RTK: Receptor tyrosine kinase.

\section{Competing interests}

AS was an employee of Merck at the time this work was initiated. AR has consulted for Merck with the honoraria paid to the institution. The other investigators have no disclosures of conflict of interest to be made.

\section{Authors' contributions}

DJLW and LR contributed equally as first authors. They designed and carried out all experiments and wrote the manuscript. MSA designed and carried out all experiments. AL and DF assisted with growth assays and western analysis. MC, EA and BC performed flow cytometric assays and flow data analysis. JT and TGG assisted with statistical analysis. GA provided help in supplemental information to AKT and mTOR inhibitor combination. AS provided SCH772984. RSL generated AR cell lines and provided critical analysis of the manuscript. All authors critically analyzed, read and approved the final manuscript.

\section{Financial support}

This work was funded by NIH grant P01 CA168585, the Ressler Family Fund, the Dr. Robert Vigen Memorial Fund, the Wesley Coyle Memorial Fund, the Garcia-Corsini Family Fund (to A.R.), and the Tower Cancer Research Foundation (to D.W.). L.R. was funded with a scholarship from Spanish Society of Medical Oncology (SEOM) for Translational Research in Reference Centers. T.G.G. is the recipient of a Research Scholar Award from the American Cancer Society (RSG-12-257-01-TBE) and an Established Investigator Award from the Melanoma Research Alliance (20120279). G.A. was funded with a scholarship from Austrian Marshall Plan Foundation.

\section{Author details}

${ }^{1}$ Department of Medicine, Division of Hematology-Oncology, University of California Los Angeles (UCLA), 11-934 Factor Building, Los Angeles, CA, USA Department of Molecular and Medical Pharmacology, UCLA, Los Angeles, CA, USA. ${ }^{3}$ Department of Surgery, Division of Surgical-Oncology, UCLA, Los Angeles, CA, USA. ${ }^{4}$ Jonsson Comprehensive Cancer Center at UCLA, 10833 Le Conte Avenue, Los Angeles, CA 90095-1782, USA. ${ }^{5}$ Discovery Oncology Merck Research Laboratories, Merck Research Laboratories, Boston, Massachusetts, USA. 'Department of Medicine, Division of Dermatology, UCLA, Los Angeles, California, USA. University of Applied Sciences, Vienna, Austria.

\section{Received: 11 February 2014 Accepted: 4 August 2014}

Published: 20 August 2014

\section{References}

1. Chapman PB, Hauschild A, Robert C, Haanen JB, Ascierto P, Larkin J, Dummer R, Garbe C, Testori A, Maio M, Hogg D, Lorigan P, Lebbe C, Jouary T, Schadendorf D, Ribas A, O'Day SJ, Sosman JA, Kirkwood JM, Eggermont AM, Dreno B, Nolop K, Li J, Nelson B, Hou J, Lee RJ, Flaherty KT, McArthur $\mathrm{GA}$ : Improved survival with vemurafenib in melanoma with braf V600e mutation. N Engl J Med 2011, 364:2507-2516.

2. Flaherty KT, Infante JR, Daud A, Gonzalez R, Kefford RF, Sosman J, Hamid O, Schuchter L, Cebon J, Ibrahim N, Kudchadkar R, Burris HA 3rd, Falchook G, Algazi A, Lewis K, Long GV, Puzanov I, Lebowitz P, Singh A, Little S, Sun P,
Allred A, Ouellet D, Kim KB, Patel K, Weber J: Combined braf and Mek inhibition in melanoma with braf V600 mutations. N Engl J Med 2012, 367:1694-1703.

3. Hauschild A, Grob JJ, Demidov LV, Jouary T, Gutzmer R, Millward M, Rutkowsk P, Blank CU, Miller WH Jr, Kaempgen E, Martin-Algarra S, Karaszewska B, Mauch C, Chiarion-Sileni V, Martin AM, Swann S, Haney P, Mirakhur B, Guckert ME, Goodman V, Chapman PB: Dabrafenib in braf-mutated metastatic melanoma: a multicentre, open-label, phase 3 randomised controlled trial. Lancet 2012, 380:358-365.

4. Heidorn SJ, Milagre C, Whittaker S, Nourry A, Niculescu-Duvas I, Dhomen N, Hussain J, Reis-Filho JS, Springer CJ, Pritchard C, Marais R: Kinase-dead braf and oncogenic Ras cooperate to drive tumor progression through craf. Cell 2010, 140:209-221.

5. Poulikakos PI, Zhang C, Bollag G, Shokat KM, Rosen N: Raf inhibitors transactivate Raf dimers and Erk signalling in cells with wild-type braf. Nature 2010, 464:427-430.

6. Nazarian $\mathrm{R}$, Shi H, Wang Q, Kong X, Koya RC, Lee H, Chen Z, Lee MK, Attar N, Sazegar H, Chodon T, Nelson SF, McArthur G, Sosman JA, Ribas A, Lo RS: Melanomas acquire resistance to B-Raf(V600e) inhibition by Rtk or N-Ras upregulation. Nature 2010, 468:973-977.

7. Shi H, Moriceau G, Kong X, Koya RC, Nazarian R, Pupo GM, Bacchiocchi A, Dahlman KB, Chmielowski B, Sosman JA, Halaban R, Kefford RF, Long GV, Ribas A, Lo RS: Preexisting Mek1 exon 3 mutations in V600e/kbraf melanomas Do Not confer resistance to braf inhibitors. Cancer Discov 2012, 2:414-424

8. Wagle N, Emery C, Berger MF, Davis MJ, Sawyer A, Pochanard P, Kehoe SM Johannessen CM, Macconaill LE, Hahn WC, Meyerson M, Garraway LA: Dissecting therapeutic resistance to Raf inhibition in melanoma by tumor genomic profiling. J Clin Oncol 2011, 29:3085-3096.

9. Johannessen CM, Boehm JS, Kim SY, Thomas SR, Wardwell L, Johnson LA, Emery CM, Stransky N, Cogdill AP, Barretina J, Caponigro G, Hieronymus H, Murray RR, Salehi-Ashtiani K, Hill DE, Vidal M, Zhao JJ, Yang X, Alkan O, Kim S, Harris JL, Wilson CJ, Myer VE, Finan PM, Root DE, Roberts TM, Golub T, Flaherty KT, Dummer R, Weber BL: Cot drives resistance to Raf inhibition through Map kinase pathway reactivation. Nature 2010, 468:968-972.

10. Shi H, Moriceau G, Kong X, Lee MK, Lee H, Koya RC, Ng C, Chodon T, Scolyer RA, Dahlman KB, Sosman JA, Kefford RF, Long GV, Nelson SF, Ribas A, Lo RS: Melanoma whole-exome sequencing identifies (V600e)B-Raf amplificationmediated acquired B-Raf inhibitor resistance. Nat Commun 2012, 3:724.

11. Poulikakos PI, Persaud Y, Janakiraman M, Kong X, Ng C, Moriceau G, Shi H, Atefi M, Titz B, Gabay MT, Salton M, Dahlman KB, Tadi M, Wargo JA, Flaherty KT, Kelley MC, Misteli T, Chapman PB, Sosman JA, Graeber TG, Ribas A, Lo RS, Rosen N, Solit DB: Raf inhibitor resistance is mediated by dimerization of aberrantly spliced braf(V600e). Nature 2011, 480:387-390.

12. Paraiso KH, Xiang Y, Rebecca WW, Abel EV, Chen YA, Munko AC, Wood E, Fedorenko IV, Sondak VK, Anderson AR, Ribas A, Palma MD, Nathanson KL, Koomen JM, Messina JL, Smalley KS: Pten loss confers braf inhibitor resistance to melanoma cells through the suppression of Bim expression. Cancer Res 2011, 71:2750-2760.

13. von Euw E, Atefi M, Attar N, Chu C, Zachariah S, Burgess BL, Mok S, Ng C, Wong DJ, Chmielowski B, Lichter DI, Koya RC, MCCannel TA, Izmailova E, Ribas A: Antitumor effects of the investigational selective Mek inhibitor Tak733 against cutaneous and uveal melanoma cell lines. Mol Cancer 2012, 11:22.

14. Atefi M, von Euw E, Attar N, Ng C, Chu C, Guo D, Nazarian R, Chmielowski B, Glaspy JA, Comin-Anduix B, Mischel PS, Lo RS, Ribas A: Reversing melanoma cross-resistance to braf and Mek inhibitors by Co-targeting the Akt/mtor pathway. PLoS One 2011, 6:e28973

15. Shi $H$, Kong X, Ribas A, Lo RS: Combinatorial treatments that overcome pdgfrbeta-driven resistance of melanoma cells to V600eb-Raf inhibition. Cancer Res 2011, 71:5067-5074.

16. Paraiso KH, Fedorenko IV, Cantini LP, Munko AC, Hall M, Sondak VK, Messina UL, Flaherty KT, Smalley KS: Recovery of phospho-Erk activity allows melanoma cells to escape from braf inhibitor therapy. Br J Cancer 2010, 102:1724-1730.

17. Sturm OE, Orton R, Grindlay J, Birtwistle M, Vyshemirsky V, Gilbert D, Calder M, Pitt A, Kholodenko B, Kolch W: The mammalian mapk/Erk pathway exhibits properties of a negative feedback amplifier. Sci Signal 2010, 3:ra90.

18. Dai B, Meng J, Peyton M, Girard L, Bornmann WG, Ji L, Minna JD, Fang B, Roth JA: Stat3 mediates resistance to Mek inhibitor through microrna Mir-17. Natl Acad Sci U S A 2011, 71:3658-3668.

19. Emery CM, Vijayendran KG, Zipser MC, Sawyer AM, Niu L, Kim JJ, Hatton C, Chopra R, Oberholzer PA, Karpova MB, MacConaill LE, Zhang J, Gray NS, 
Sellers WR, Dummer R, Garraway LA: Mek1 mutations confer resistance to Mek and B-Raf inhibition. Cancer Res 2009, 106:20411-20416.

20. Wang H, Daouti S, Li WH, Wen Y, Rizzo C, Higgins B, Packman K, Rosen N, Boylan JF, Heimbrook D, Niu H: Identification of the Mek1(F129l) activating mutation as a potential mechanism of acquired resistance to Mek inhibition in human cancers carrying the B-Rafv600e mutation. Cancer Res 2011, 71:5535-5545.

21. Ascierto PA, Schadendorf D, Berking C, Agarwala SS, van Herpen CM, Queirolo P, Blank CU, Hauschild A, Beck JT, St-Pierre A, Niazi F, Wandel S, Peters M, Zubel A, Dummer R: Mek162 for patients with advanced melanoma harbouring nras or Val600 braf mutations: a Non-randomised, open-label phase 2 study. Lancet Oncol 2013, 14:249-256.

22. Falchook GS, Lewis KD, Infante JR, Gordon MS, Vogelzang NJ, DeMarini DJ, Sun P, Moy C, Szabo SA, Roadcap LT, Peddareddigari VG, Lebowitz PF, Le NT, Burris HA 3rd, Messersmith WA, O'Dwyer PJ, Kim KB, Flaherty K, Bendell $J C$, Gonzalez R, Kurzrock R, Fecher LA: Activity of the oral Mek inhibitor trametinib in patients with advanced melanoma: a phase 1 dose-escalation trial. Lancet Oncol 2012, 13:782-789.

23. Hall J, Hashibe M, Boffetta P, Gaborieau V, Moullan N, Chabrier A, Zaridze D, Shangina O, Szeszenia-Dabrowska N, Mates D, Janout V, Fabianova E, Holcatova I, Hung RJ, McKay J, Canzian F, Brennan P: The association of sequence variants in DNA repair and cell cycle genes with cancers of the upper aerodigestive tract. Cell Physiol 2007, 28:665-671.

24. Rozengurt E: Mitogenic signaling pathways induced by $\mathrm{G}$ proteincoupled receptors. Carcinogene 2007, 213:589-602.

25. Meloche S, Pouyssegur J: The Erk1/2 mitogen-activated protein kinase pathway as a master regulator of the G1- to S-phase transition. Oncogene 2007, 26:3227-3239.

26. Mendoza MC, Er EE, Blenis J: The Ras-Erk and Pi3k-mtor pathways: cross-talk and compensation. Trends Biochem Sci 2011, 36:320-328.

27. Jiang Z, Zhang Y, Chen X, Lam PY, Yang H, Xu Q, Yu AC: Activation of Erk1/2 and Akt in astrocytes under ischemia. Biochem Biophys Res Commun 2002, 294:726-733.

28. Carriere A, Romeo Y, Acosta-Jaquez HA, Moreau J, Bonneil E, Thibault P, Fingar DC, Roux PP: Erk1/2 phosphorylate raptor to promote Ras-dependent activation of mtor complex 1 (Mtorc1). J Biol Chem 2011, 286:567-577.

29. Zoncu R, Efeyan A, Sabatini DM: Mtor: from growth signal integration to cancer, diabetes and ageing. Nat Rev Mol Cell Biol 2011, 12:21-35.

30. Morris EJ, Jha S, Restaino CR, Dayananth P, Zhu H, Cooper A, Carr D, Deng Y, Jin W, Black S, Long B, Liu J, Dinunzio E, Windsor W, Zhang R, Zhao S, Angagaw MH, Pinheiro EM, Desai J, Xiao L, Shipps G, Hruza A, Wang J, Kelly J, Paliwal S, Gao X, Babu BS, Zhu L, Daublain P, Zhang L: Discovery of a novel Erk inhibitor with activity in models of acquired resistance to braf and Mek inhibitors. Cancer Discov 2013, 3:742-750.

31. Sondergaard JN, Nazarian R, Wang Q, Guo D, Hsueh T, Mok S, Sazegar H, MacConaill LE, Barretina JG, Kehoe SM, Attar N, von Euw E, Zuckerman JE, Chmielowski B, Comin-Anduix B, Koya RC, Mischel PS, Lo RS, Ribas A: Differential sensitivity of melanoma cell lines with Brafv600e mutation to the specific Raf inhibitor Plx4032. J Trans/ Med 2010, 8:39.

32. Carlino MS, Todd JR, Gowrishankar K, Mijatov B, Pupo GM, Fung C, Snoyman S, Hersey P, Long GV, Kefford RF, Rizos H: Differential activity of Mek and Erk inhibitors in braf inhibitor resistant melanoma. Mol Cancer Ther 2014, 8:544-554.

33. Hatzivassiliou G, Liu B, O'Brien C, Spoerke JM, Hoeflich KP, Haverty PM, Soriano R, Forrest WF, Heldens S, Chen H, Toy K, Ha C, Zhou W, Song K, Friedman LS, Amler LC, Hampton GM, Moffat J, Belvin M, Lackner MR: Erk inhibition overcomes acquired resistance to Mek inhibitors. Mol Oncol 2012, 11:1143-1154.

34. Lassen A, Atefi M, Robert L, Wong DJ, Cerniglia M, Comin-Anduix B, Ribas A: Effects of Akt inhibitor therapy in response and resistance to braf inhibition in melanoma. Mol Cancer 2014, 13:83.

35. Chou TC, Talalay P: Quantitative analysis of dose-effect relationships: the combined effects of multiple drugs or enzyme inhibitors. Adv Enzyme Regul 1984, 22:27-55.

doi:10.1186/1476-4598-13-194

Cite this article as: Wong et al: Antitumor activity of the ERK inhibitor SCH722984 against BRAF mutant, NRAS mutant and wild-type melanoma. Molecular Cancer 2014 13:194.

\section{Submit your next manuscript to BioMed Central and take full advantage of:}

- Convenient online submission

- Thorough peer review

- No space constraints or color figure charges

- Immediate publication on acceptance

- Inclusion in PubMed, CAS, Scopus and Google Scholar

- Research which is freely available for redistribution 